\title{
Vizualizing the Nation, Gender, Representation, and Revolution in Eighteenth Century France
}

Jean-Clément Martin

\section{(2) OpenEdition \\ 1 Journals}

Édition électronique

URL : https://journals.openedition.org/ahrf/2258

DOI : 10.4000/ahrf.2258

ISSN : 1952-403X

Éditeur :

Armand Colin, Société des études robespierristes

Édition imprimée

Date de publication : 1 juin 2002

Pagination : 231-232

ISSN : 0003-4436

Référence électronique

Jean-Clément Martin, «Vizualizing the Nation, Gender, Representation, and Revolution in Eighteenth Century France ", Annales historiques de la Révolution française [En ligne], 328 | avril-juin 2002, mis en ligne le 11 mai 2006, consulté le 23 avril 2022. URL : http://journals.openedition.org/ahrf/2258 ; DOI https://doi.org/10.4000/ahrf.2258

Ce document a été généré automatiquement le 23 avril 2022.

Tous droits réservés 


\title{
Vizualizing the Nation, Gender, Representation, and Revolution in Eighteenth Century France
}

\author{
Jean-Clément Martin
}

\section{RÉFÉRENCE}

Joan Landes, Vizualizing the Nation, Gender, Representation, and Revolution in Eighteenth Century France, Cornell University Press, 2001, 254 p.

1 Joan Landes est bien connue pour ses travaux dans les Gender Studies, depuis son célèbre Women and the Public Sphere in the Age of the French Revolution, paru en $1988 \mathrm{chez}$ le même éditeur. Avec ce livre elle rouvre la question de la place des femmes dans le processus révolutionnaire ou plutôt celle des rapports hommes/femmes en interrogeant l'iconographie politique à la fin du xvIII ${ }^{e}$ siècle. En questionnant le rapport entre culture politique et iconographie, l'auteur réfléchit aussi sur l'iconographie comme mode de connaissance de l'histoire, à côté des textes. La démarche n'est certes pas inédite en France depuis les ouvrages d'A. de Baecque, de Ph. Bordes, de C. Langlois et d'A. Duprat, mais elle a le mérite de rappeler encore une fois que la politique, ou plutôt la politisation, se fait par les sentiments et les émotions autant si ce n'est plus que par les raisonnements philosophiques et les débats. L'objectif du livre est plus large et plus ambitieux, il s'agit de montrer en quoi l'iconographie du corps de la femme telle qu'elle est proposée dans cette période change le sens même des symboles car si les femmes ainsi représentées remplacent les saintes de la religion, l'image de leurs corps leur assigne une place particulière dans la sphère publique, tout en servant à attacher les hommes à la République et à la nation. L'iconographie n'est donc ni une illustration, ni un outil, mais bien le vecteur d'une leçon politique que les discours et les textes n'osent pas donner. Il s'agit là d'un point de méthode important, posant le pouvoir des images au même titre que celui des discours. L'auteur se situe dans la ligne des travaux de George Mosse qui a montré comment la moralité et la sexualité ont changé avec 
l'apparition du nationalisme, la chasteté, la fidélité étant désormais dédiées à la nation. Ainsi, si la position de la femme décline dans la société du XVIII ${ }^{e}$ siècle, la représentation de la nation sous des traits féminins a érotisé la relation à la nation.

2 Au travers de quatre chapitres consacrés à l'image comme argument dans la culture, à la femme comme représentation du corps politique, comme incarnation des vertus féminines et l'emploi de l'iconographie pour lier nationalisme et sexualité, le livre pose donc selon ce point de vue le problème de la place des femmes/de la femme dans le champ politique. Celles-ci sont des citoyens passifs, sans possibilité d'intervenir du fait de la crainte de la séduction qu'elles sont censées exercer et de l'erreur dans laquelle elles peuvent conduire les hommes. Mais le corps des femmes ne cesse d'être vu et montré par les hommes, ce qui fait de lui le lieu d'un exercice du pouvoir.

D'une part, cette démonstration passe par la dépréciation de la féminité dans des caricatures et des allégories qui utilisent le corps des femmes pour condamner la noblesse. Les corps sont ainsi soumis à des démembrements, à des mises en scène pornographiques ou scatologiques - avant d'être remembrés politiquement. Le corps féminin sert à souligner la faiblesse de la noblesse en même temps qu'à sanctifier la liberté nouvelle, mais il s'agit d'une métaphore non d'une métonymie, la femme ne profitant pas du tout du symbole dont elle est chargée.

4 Par l'iconographie, la critique est vive aussi contre les femmes qui s'aventurent en politique ou dans la lutte. Elles sont présentées alors comme des amazones, au lieu d'être ces femmes raisonnables qui lisent dans leur salon, le rire et la dérision fixant leur rôle dans les tâches domestiques et maternelles. La férocité se déchaîne même contre la liberté féminine: la femme est alors présentée comme débauchée, corruptrice, aristocrate ou reine ! Et vouée au viol par le patriote !

D'autre part, un autre registre insiste sur la représentation de la femme comme emblème de la patrie. Il s'agit alors de l'image de la femme décente, maternelle, désexualisée, qui va alors de pair avec la virilisation de l'homme. En même temps, cette image porte une charge érotique qui permet de comprendre l'attachement émotionnel qui se produit autour de l'incarnation de la nation et du lien charnel qui va s'établir entre les citoyens et leur pays. Le livre est appuyé sur une iconographie importante, bien connue pour l'essentiel, J.Landes ajoutant une lecture sexuée de l'iconographie qui est tout à fait pertinente et qui concorde avec d'autres travaux, contribuant à valider cette problématique importante. 